\title{
NEGOCIAR LAS DISTINCIONES. UNA ETNOGRAFÍA SOBRE GÉNERO Y CUIDADOS EN UN TALLER DE BORDADOS PARA SEÑORAS MAYORES EN PROVIDENCIA (CHILE)
}

\author{
NEGOTIATING DISTINCTIONS. AN ETHNOGRAPHY ON GENDER \\ AND CARE IN AN EMBROIDERY WORKSHOP FOR ELDERLY \\ LADIES IN PROVIDENCIA (CHILE)
}

\author{
Herminia Gonzálvez Torralbo ${ }^{1}$, Sofia Larrazabal Bustamante ${ }^{2}$ y Menara Guizardi ${ }^{3,4}$
}

\begin{abstract}
Presentamos un estudio de caso etnográfico realizado entre 2016 y 2017 junto a mujeres mayores que participaban de talleres de tejido y bordado en un centro comunitario de la Comuna de Providencia (Región Metropolitana, Chile). La investigación indagaba sobre las prácticas, saberes y significados articulados a través de las relaciones de cuidado entre mujeres pertenecientes a sectores sociales de estratificación mediana y alta. Nuestro objetivo fue comprender cómo la vejez era vivida por estas mujeres; y cuáles estrategias comunitarias, personales y familiares desarrollaban para hacer frente a los desafíos y posibilidades del envejecimiento. Para abordar nuestros resultados, partimos por describir en la segunda sección la metodología del estudio y por sintetizar, en la tercera sección, los debates sobre género y envejecimiento en las ciencias sociales. En la cuarta sección, describimos el contexto de Providencia en sus aspectos sociodemográficos, económicos, en sus políticas públicas destinadas a la población mayor. En la quinta y sextas secciones, adentrando en nuestra experiencia etnográfica feminista, retomaremos los relatos de las mujeres sobre los cuidados y las articulaciones políticas que permean sus vidas. Finalizamos con reflexiones que, a luz de los datos etnográficos, redimensionan y expanden algunas de las contribuciones específicas de los debates teóricos actuales.
\end{abstract}

Palabras claves: etnografía feminista, cuidados, género, envejecimiento, Comuna Providencia, Chile.

The article presents an ethnographic case study carried out between 2016 and 2017 with elderly women who participated in weaving and embroidery classes in a community center in the district of Providencia (Metropolitan Region, Chile). The research investigated practices, knowledge, and meanings articulated through care relationships among women from medium and high social strata. We aim to understand how aging was experiencied by these women of Providencia, inquiring the strategies they developed at the community, personal, and family level to face the challenges and possibilities of aging. To address the results of our research, we will start by describing, in the second section, the research methodology, and then, in the third section, we will synthesize the debates on gender and aging in the social sciences. The fourth section describes the sociodemographic, economic and public policy aspects of Providencia regarding its elderly population. The fifth and sixth sections further explore our ethnographic feminist experience, detailing the narratives of the women regarding care, and the political articulations that permeate their lives. We conclude with reflections based on the ethnographic data, and wich expand some of specific contributions of the current theoretical debates.

Key words: Feminist, ethnography, care, gendel, aging, providencia, Chile.

La experiencia social de la vejez viene ganando relevancia política e investigativa en los últimos años en Chile (Ministerio de Desarrollo Social [MIDESO] 2013, 2015). El envejecimiento de la población y la feminización de dicho envejecimiento constituyen un tema sociopolítico a la par que científico, que está siendo abordado como un desafío para el país tanto desde la política pública (Arriagada 2007, 2010, 2011; Forttes 2016) como desde la academia, que viene investigando las varias dimensiones cualitativas de sus consecuencias desde diferentes prismas (Gallardo-Peralta et al. 2015, 2017; Gonzálvez 2017,

\footnotetext{
${ }^{1}$ Facultad de Derecho y Humanidades, Vicerrectoría académica, Universidad Central de Chile, Santiago, Chile. herminiagonzalvez@gmail.com

${ }^{2}$ Centro de Justicia Educacional, Región Metropolitana, Santiago, Chile. sofia.larrazabal@ gmail.com

${ }^{3}$ Instituto de Altos Estudios Sociales de la Universidad Nacional de San Martín (Becaria CONICET), Buenos Aires, Argentina. menaraguizardi@yahoo.com.br

${ }^{4}$ Universidad de Tarapacá, Arica, Chile.
} 
2018; Osorio 2018; Retamales 2018; Sánchez et al. 2018).

Para el quinquenio 2005-2010, el país presentaba la mayor tasa de esperanza de vida al nacer de América Latina: 79,4 años. En 2016, alcanzó los 80,5 años, solo superado en las Américas por Canadá (Organización Mundial de la Salud [OMS] 2016). El Índice de Adulto Mayor (IAM), que establece la proporción de personas mayores por cada 100 habitantes menores de 15 años, indica que, para el año 1990, había 30 personas mayores por cada 100 niños en Chile. En 2010, la proporción pasó a 59,1/100 y, en 2012, a 67,1/100 (Ganga et al. 2016). Según el Censo 2017, de un total de 17.574.003 personas computadas en el país, 2.850.171 tenían 60 años o más (Instituto Nacional de Estadísticas [INE] 2017).

Por otro lado, el envejecimiento se presenta marcado por la condición de género en Chile. Según el Censo 2017, hay en el país 95,9 hombres por cada 100 mujeres. Pero, la proporción femenina se incrementa notablemente en la población más envejecida. Entre los mayores de 60 años, $56,8 \%$ son mujeres y $43,13 \%$ son hombres (INE 2017). Las mujeres de esta franja etaria están menos cubiertas por la jubilación (Programa de Naciones Unidas Para el Desarrollo [PNUD] 2017:25) y, cuando lo están, reciben valores un 30\% inferiores a los masculinos (PNUD 2017:333). Debido a todos estos factores, Chile viene atravesando una "crisis demográfica" caracterizada por la "feminización del envejecimiento" (Fernández y Kehl 2001:132). Asimismo, el diagnóstico sobre la desigualdad en Chile, realizado por el Programa de las Naciones Unidas para el Desarrollo (PNUD 2017), apunta que cerca del $72 \%$ de los jubilados recibe un estipendio inferior a la pensión mínima determinada por ley (que equivale al 70\% del sueldo mínimo nacional) (PNUD 2017:25). Las bajas pensiones generan una sensación de inseguridad ciudadana, especialmente para las poblaciones de los dos quintiles más pobres.

Pero, poco se sabe sobre el envejecimiento en aquellos sectores sociales de renta elevada, donde los problemas vinculados al avance de la edad se asocian a problemáticas relacionales, a la necesidad de reorganizar las cadenas de cuidado o de negociar el reconocimiento y las formas de participación en los espacios de representación social y política (Iacub y Arias 2010; Prieto et al. 2015; Serrat et al. 2017). El presente artículo ofrece una contribución exploratoria e inicial a estos aspectos. Presentamos resultados de un estudio de caso etnográfico que buscaba comprender la experiencia de los cuidados entre mujeres mayores de la Comuna de Providencia, en la Región Metropolitana de Chile (RM). Providencia está caracterizada por presentar condiciones económicas superiores a la media nacional chilena, contando con una población mayoritariamente situada en niveles de estratificación social mediana y elevada.

Nuestro objetivo central fue comprender cómo la vejez era vivida por las mujeres de este sector social específico y cuáles estrategias desarrollaban para hacer frente a los desafíos vinculados al envejecimiento. Nuestros objetivos específicos eran observar en qué medida el envejecimiento provocaba, para las mujeres que habitan en esta comuna, procesos de renegociación (1) de sus distinciones sociales; (2) de los cuidados que entregaban; (3) de sus prácticas de autocuidado. Así, nuestra investigación se plantea también como un estudio de caso de sectores clasificados como "élites": "un grupo relativamente pequeño dentro de la jerarquía social que reclama y/o al cual se le otorga poder, prestigio o mando sobre otros sobre la base de una serie de criterios reconocidos públicamente, teniendo como objetivo preservar y afianzar su estatus" (Salverda y Abbkink 2013:1-2).

Para abordar los resultados de este estudio, partiremos describiendo, en la segunda sección, la metodología adptada en la investigación. En la tercera, sintetizamos los debates sobre género, envejecimiento, participación política y distinciones en las ciencias sociales. El cuarto apartado describe el contexto de Providencia en sus aspectos sociodemográficos vinculados a la población mayor y los talleres de bordado y tejido. El quinto aborda los relatos de las mujeres mayores que frecuentan estos talleres con relación al género y los cuidados que ellas prestan y reciben. El sexto dilucida las articulaciones políticas que se entretejen en los talleres y a través de la vida de estas mujeres. Finalizamos con reflexiones que, a luz de los datos etnográficos, redimensionan los debates teóricos presentados.

\section{Metodología}

Para atender a los objetivos del estudio, participamos, entre 2016 y 2017, de los talleres de tejido y bordado frecuentados por mujeres mayores en un centro comunitario administrado por la municipalidad de Providencia. Las características que componen el perfil de las participantes del taller se detallan en la Tabla 1, registrada mediante entrevistas personales y notas de campo. Allí, accedimos a la experiencia de mujeres con más alta renta que, en su mayoría, tenían vivencias del envejecimiento cubiertas por sistemas públicos y privados de protección social (que, conforme explicitamos en la introducción, no constituyen una realidad extendida en Chile).

En términos metodológicos, nuestra investigación estuvo orientada por la etnografía feminista. Esta metodología demanda un tipo particular de postura asumida por las investigadoras, focalizando el 


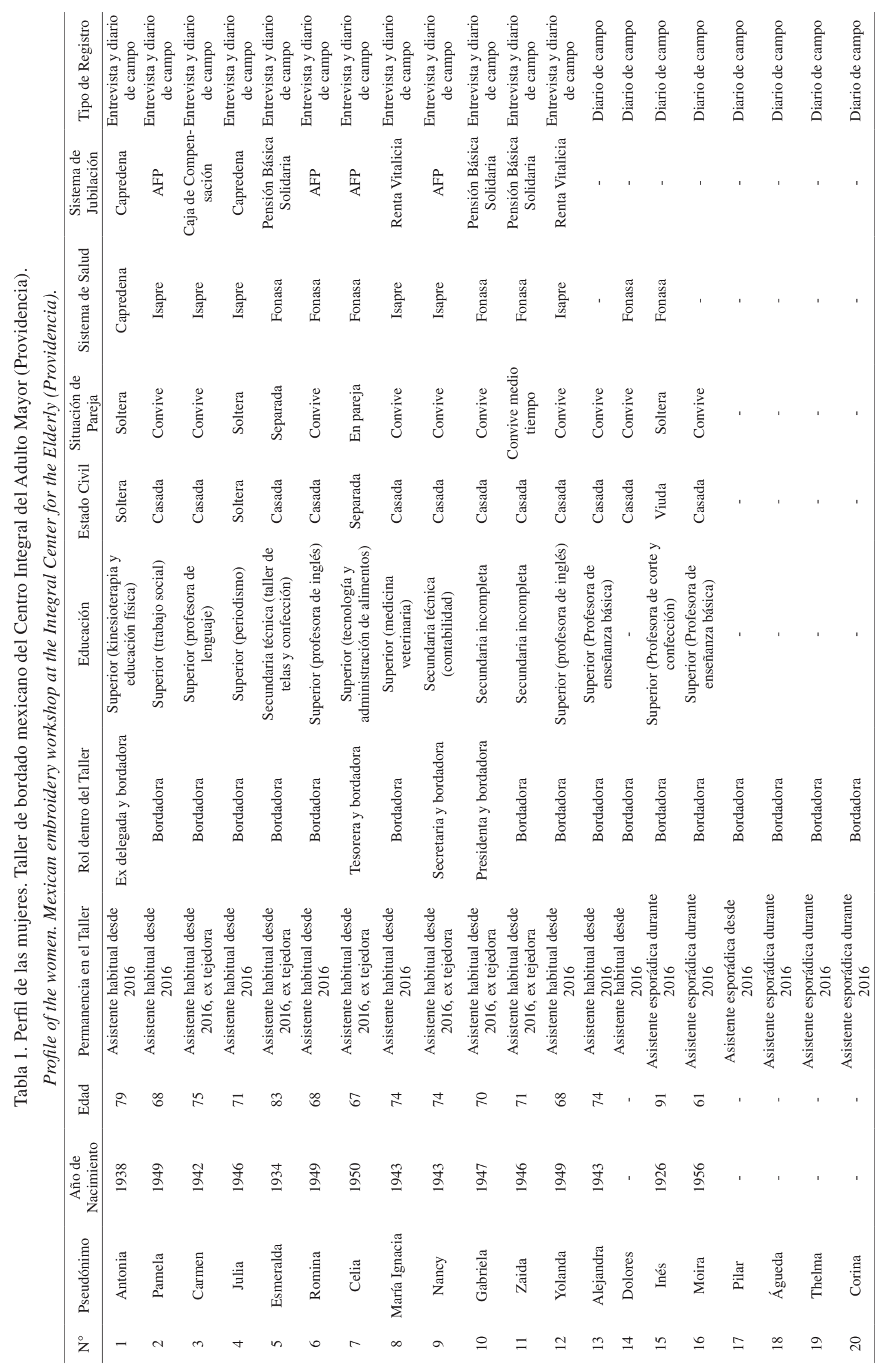


saber vivencial implicado y comprometido con las personas estudiadas (Gregorio y Alcázar 2014:2). En este abordaje, la vinculación entre investigadoras e investigadas es de carácter intersubjetivo (Bell 1993), conllevando lazos éticamente responsables y comprometidos. Para ello, nuestra etnografía estuvo particularmente guiada por una "perspectiva feminista desde abajo", atenta a la contradicción de la figura de autoridad de las investigadoras -reconociendo el lugar de subordinación que nosotras ocupamos en el mundo académico debido a nuestra condición de género (Behar 1995:2)-y también a los matices políticos del proceso de constitución de las subjetividades entre las personas estudiadas (Visweswaran 2003:74). A través de esta perspectiva buscamos:

restituir el valor del saber vivencial, implicado y comprometido. Un saber desde el que la razón y la emoción no sean dos polos distinguibles y contrapuestos como el pensamiento occidental androcéntrico y etnocéntrico nos quiere hacer creer, sobredimensionando el valor de lo "racional" frente a lo "emocional", lo científico frente a lo no-científico y en el fondo lo masculino, en su asociación aristotélica con la razón, frente a lo femenino en su asociación con lo emocional (Gregorio y Alcázar 2014:2).

Esto supuso, asumir la etnografía no como "observación participante" (como supone su versión más clásica, malinoswskiana), sino como "participación observante" (Tedlock 1991:69). La diferencia entre estas posturas radica en que:

durante la observación participante, los etnógrafos intentan ser participantes emocionalmente comprometidos y observadores fríamente desapasionados de las vidas de los otros. En la participación observante, los etnógrafos experimentan y observan su propia coparticipación y la de otros en el encuentro etnográfico. El cambio de una metodología a otra implica una transformación representacional en que, en lugar de elegir entre escribir una memoria etnográfica centrada en el Yo [self] o una monografía estándar centrada en el Otro, tanto el Yo como el Otro se presentan juntos en una narrativa etnográfica única, centrada en el carácter y proceso del diálogo etnográfico (Tedlock 1991:69, traducción propia).

Así, nuestra práctica etnográfica en las visitas a los talleres difiere de la "etnográfica clásica" en aspectos procedimentales y epistemológicos fundamentales. $\mathrm{La}$ razón por la cual adoptamos esta metodología y no otras refiere a tres aspectos centrales. Por un lado, a nuestro posicionamiento ético crítico (al reconocimiento del lugar intersubjetivo que compartimos con estas mujeres en cuanto adscriptas a una identidad genérica femenina), el cual nos implica trabajar la intersubjetividad en la etnografía como un elemento que es, simultáneamente, una evidencia empírica y una configuración políticoepistemológica (Segato 2013). En segundo lugar, porque la etnografía se presenta como una metodología particularmente fructífera para el abordaje progresivo de temas sensibles, cuya explicitación, por parte de los sujetos, demanda la consolidación de lazos de confianza hacia las investigadoras (Abu-Lughod 1990; Gregorio y Alcázar 2014; Naples 2013; Tedlock 1991). Por otro lado, la etnografía es también un método que ha mostrado resultados contundentes en estudios que buscan captar la vinculación entre la experiencia subjetiva y la transición generacional entre etapas vitales (Johnson-Hanks 2002).

Partiendo de estos posicionamientos metodológicos, Larrazabal y Gonzálvez frecuentaron las clases de bordado mexicano por un total de diez meses: entre agosto de 2016 y enero de 2017 y, luego, entre agosto de 2017 y enero de 2018. Las clases se realizaban los martes y jueves, de las 15:00h a las 17:00h. Las investigadoras registraron sus experiencias en 36 notas extensas de campo, en las que se desglosan las informaciones generales del taller y referente a la vida y a las actividades diarias de sus integrantes ${ }^{1}$. Guizardi adentró al proceso investigativo una vez finalizado el campo, para realizar junto con las investigadoras mencionadas, el análisis y triangulación de los datos empíricos. En este proceso, todo el material fue tratado mediante análisis de contenido a partir de categorizaciones emergentes y reincidentes, construyéndose para tal una estructura matricial y jerárquica a través del software MaxQDA.

Este trabajo analítico sobre los diarios nos devolvió un entramado de temas que eran recurrentes en las conversaciones que las mujeres sostenían entre sí y en las que mantenía con las investigadoras. Dichos temas aparecen en el presente artículo recuperados a través de la estructura semántico-interpretativa de nuestros sujetos de investigación. Esto significa que la narración etnográfica que desarrollaremos en los apartados centrales de este artículo sigue una lógica descriptiva emic ${ }^{2}$ : reproduce la lógica organizativa que fuimos observando en los propios diálogos de las mujeres. En este sentido, nuestra presentación de los temas emergentes no es ni aleatoria, ni ingenua: es una forma de describir, desde la narración de los resultados, una manera específica de ordenar temas semánticos que remonta a las mujeres que son sujetos de nuestro estudio ${ }^{3}$. Es, al mismo tiempo, una forma particular de tensionar la dicotomía analítica emic-etic en antropología.

Si bien esta narración puede resultar "desordenada" según la perspectiva de las ciencias sociales de 
corte positivista, ella entrega una información empírica fundamental sobre los modos de entretejer simbólicamente temas y significados por parte de los sujetos. Este uso narrativo particular responde a nuestra adhesión a las prácticas de la etnografía feminista crítica (sobre esto, ver, específicamente McNamara 2009). Así, convocamos a los y las lectoras a leer nuestras descripciones etnográficas en los apartados que siguen considerando esta especificidad epistemológica de nuestra narración, reflejo propio de una posición antropológica crítica e intersubjetiva.

Esta misma postura interpretativa es requerida para la lectura de algunos términos que usamos para designar a las mujeres y que fueron elegidos por ellas mismas. En antropología social y cultural, desde los años sesenta (Berreman 1966; Dundes 1962; Harris 1976), se comprende que las formas de representar a los grupos y personas no es universal, sino que situacionalmente cultural. Esto significa que las identidades son situaciones y, por lo mismo, lo son también las maneras de designarlas. Cuando mencionamos a las mujeres con las cuales trabajamos en nuestra etnografía como "señoras" y como "doñas", lo hacemos porque así se trataban entre sí y así nos pedían ser tratadas. Estos son usos lingüísticos "emic".

\section{Feminización del Cuidado y Distinciones Sociales en la Vejez}

La emergencia de un campo de estudios sobre la vejez en la investigación profesional remite a la estructuración, desde 1940, de la gerontología (Arquiola 1995:154). Esta última, derivada de las ciencias biológicas y de la salud, se acercó progresivamente a los debates y perspectivas sociales, en una crítica a las bases positivistas (y biologizantes) de su surgimiento disciplinario (Yuni y Urbano 2008:153). Es en Estados Unidos, entre 1940 y 1960, que la gerontología inaugurará una primera generación de categorías analíticas vinculando la vejez a los debates sociológicos. Estos primeros análisis incluían "las teorías de la actividad, de la desvinculación, de la modernización y de la subcultura de la vejez" (Yuni y Urbano 2008:152). Entre 1950 y 1960, estos trabajos expandieron la mirada, indagando sobre la experiencia de envejecimiento en su vinculación con fenómenos como la pobreza, el abandono familiar o la exclusión social (Osorio 2006:7). A partir de 1960, la llamada "Teoría de la Desvinculación”, de Cummings y Henry (1961), emerge como paradigma hegemónico sobre el envejecimiento -posición que detentaría por medio siglo (Osorio 2006:7). $\mathrm{Su}$ argumento establece que la vejez está socialmente construida a través de una exclusión fundante. El proceso de "desvinculación" del mercado laboral vivido por los mayores (dada la jubilación) les empujaría a una condición social periférica, determinando que su acceso a bienes de consumo, relaciones sociales y dinámicas colectivas esté permanentemente demarcado por su "no participación" en el mundo productivo.

En América Latina, la vejez configuró un tema de estudios para la demografía, psicología, medicina y gerontología desde los años setenta (Aranibar 2001). Les siguieron en este interés la sociología y antropología, en la misma década (Lins de Barros 2006). Actualmente, en las ciencias sociales latinoamericanas, las formas de abordaje del envejecimiento son heterogéneas, atravesadas por disensos (Sánchez-Nítola y RamírezCortázar 2019). Tanto en Latinoamérica como en otras regiones, una de las principales acusaciones críticas sobre los estudios en este campo se refieren a que, en muchos de ellos, los argumentos tienden a replicar de forma acrítica imaginarios predominantes en los contextos donde fueron producidos (Hutheesing 1993; Fernández y Kehl 2001; Marshall 2006). Desde los sesenta, diversos investigadores empezaron a poner en prensa su crítica a estas lecturas, alertando que ellas se basan en imaginarios de discriminación por edad. Butler (1969) acuñó el término "Age-Ism" [edadísmo] para referirse a estos imaginarios, observando que ellos redundan: (1) en la invisibilización del papel de las personas mayores en diversos ámbitos; (2) en la generalización de las necesidades y demandas de esta población sin considerarlas interseccionalmente a la luz de categorizaciones como el género, la clase y la raza (Calasanti et al. 2006). Con todo, en las investigaciones anglófonas predominaron, hasta los años noventa, definiciones pesimistas que asocian el envejecimiento a la dependencia (Hutheesing 1993), al fracaso personal, pérdida de atractivo físico y pobreza (Rosenthal 1990; Calasanti et al. 2006; Montero y Bedmar 2010). Esta representación de la vejez como un "problema social" también se ha reproducido en América Latina (Araníbar 2001; Sánchez-Nítola y Ramírez-Cortázar 2019). Estas lecturas oscurecen los aspectos positivos vinculados a esta etapa vital, potenciando discursos que reproducen discriminaciones por edad (Ginn y Arber 1991).

En Chile, diversos autores concuerdan con que las definiciones de la vejez están influidas por imaginarios sociales que la encasillan como una etapa improductiva y frágil: de dependencia, pasividad, declive sexual y dificultades de adaptación a nuevos contextos sociales y tecnológicos (Arnold-Cathalifaud et al. 2007; GallardoPeralta et al. 2015, 2017; Gonzálvez 2017, 2018; Osorio et al. 2018; Retamales 2018). Estos estereotipos impactan la experiencia vital de los y las mayores, afectando su inserción al mercado laboral (Nazar y Figueroa 2015:124). Lo anterior es muy relevante en un país donde el $72 \%$ de los jubilados no logra sobrevivir con sus pensiones (PNUD 2017).

La introducción de una perspectiva de género sobre el envejecimiento fue tardía en las ciencias sociales 
(Marshall 2006), implicando la reproducción de lecturas androcéntricas vinculadas al edadísmo (Gibson 1996:433). Es solo en los ochenta cuando se produce un giro epistémico que centraliza la dimensión femenina del fenómeno en las investigaciones sociales (Osorio 2007). Este giro comienza con la suposición de que el sexo y la edad "forman la base sobre la cual las identidades de las personas se establecen y sobre la cual comienzan las líneas de comunicación y locación social" (Levy 1988:480). Así, los significados negativos asociados a las personas mayores afectarían a las mujeres diferencialmente, debido a su condición de doble subalternidad: de género y de edad (Gonzálvez 2017, 2018). Estas cuestiones relacionadas con el mayor o menor acceso al bienestar a lo largo de la vida de las mujeres nos llevan a indagar sobre la relación entre cuidados y envejecimiento en contextos en los que ambos se presentan feminizados, como en Chile (Gajardo 2015; Gonzálvez 2018).

¿Por qué los cuidados son centrales para entender la experiencias femeninas de la vejez? Para responder a esta pregunta, debemos, primero, definir el concepto. Los "cuidados" constituyen una categoría polisémica (Arriagada 2010, 2011; Duffy 2011). Equivalen a "las actividades y relaciones que se desarrollan" para "satisfacer las necesidades físicas y emocionales de las personas" (Del Valle 2013:30). Son "multidimensionales" y "cotidianos", engendrando todos los aspectos necesarios para la sostenibilidad de la vida (Huenchuán 2014:153). Así, las necesidades de cuidado son básicas para la reproducción vital y tienen un carácter intergeneracional (Glenn 2010:5). Ya sea porque miembros de diferentes generaciones se cuidan entre sí, o porque la necesidad de ser cuidado atraviesa todos los ciclos vitales, aunque transformándose en todos ellos (Izquierdo 2003:12). El cumplimiento de estas necesidades puede hacerse de forma continuada o esporádica, pero apunta a resolver situaciones de dependencia (Comas 2017:20). El acto de cuidar y de ser cuidado involucra, además, la producción de afectos (England 2005:389) y de responsabilidades combinadas (Duffy 2011:9)

Estas definiciones reiteran la transversalidad de la desigualdad de género. Pero la reproducción de esta desigualdad está siendo cuestionada debido a la crisis de los cuidados que se observa en contextos como el chileno (Arriagada 2007, 2010, 2011). Con "crisis de los cuidados", referimos a la incapacidad de construir salidas articuladas para las necesidades presentadas por la población (Pérez-Orozco 2006). Los factores que configuran esta crisis pueden rastrearse a través de tres ejes: (1) las transformaciones sociodemográficas que consolidan un incremento de la longevidad poblacional y de la demanda de cuidados ${ }^{5}$; (2) la adopción de directrices políticas neoliberales que, al incluir recortes sociales vigorosos, limitan la cobertura entre demanda y oferta de cuidados (Pérez-Orozco 2006:3); (3) los cambios sociolaborales que provocan la disminución de la disponibilidad de mujeres que ofrezcan cuidados, debido al aumento de su ingreso al mercado laboral (Ezquerra 2012).

Este cuadro pone en evidencia al menos cuatro apreciaciones bastante naturalizadas sobre la relación entre las familias y los cuidados: (1) que los trabajos del cuidado debieran circunscribirse al "espacio privado", acotándose a la intimidad familiar (Filgueira 2009:112); (2) que las mujeres serían las responsables de ellos dentro y fuera de las familias (Aronson 1992; Arriagada 2010; Glenn 2010; Treviño et al. 2006); (3) la desconfiguración de las fronteras entre trabajos de cuidado, domésticos y reproductivos, asumidos frecuentemente como intercambiables entre sí (Duffy 2011:12); y, (4) la centralización del afecto (entendido también en cuanto práctica "femenina") como un elemento estructurante de los contenidos y motivaciones del cuidado, en oposición a los trabajos "más racionalizados" vinculados a la "esfera pública" (asociados a la masculinidad, productividad y mercado) (Duffy 2011:12). En el curso de vida de las mujeres, las labores del cuidado constituyen actividades no remuneradas y sin reconocimiento social (Aronson 1992; Aguirre 2007; Glenn 2010; Duffy 2011; Comas 2017), que las empujan hacia procesos de marginación y vulneración (Flores et al. 2012; Organización Internacional del Trabajo [OIT] 2009; Servicio Nacional del Adulto Mayor [SENAMA] 2010). Las responsabilidades de provisión de cuidados se prolongan e intensifican en el envejecimiento: las mujeres mayores son presionadas a actuar como cuidadoras -de sus nietos/as, parejas e hijos/as, por ejemplo-, pese a necesitar también ellas de cuidados (Glenn 2010).

Desde inicios del siglo XXI, la Organización Mundial de la Salud (OMS) viene proponiendo incluir visiones no edadístas de la vejez en la planificación de las políticas públicas y también en la elaboración, desde los diversos campos científicos, de diagnósticos sociales sobre los problemas enfrentados por la población envejecida (entre ellos, los referentes a las demandas y organización del cuidado). Uno de los conceptos propuestos por la OMS en el marco de esta redefinición es el de "envejecimiento activo". La expresión alude al "proceso de optimización de las oportunidades de salud, participación y seguridad con el fin de mejorar la calidad de vida a medida que las personas envejecen" (OMS 2002:99). El término "activo" hace referencia a una "participación continua en las actividades sociales, económicas, culturales, espirituales y cívicas, no sólo a la capacidad para estar físicamente activo o participar en el mercado de trabajo" (OMS 2002:99). Así, tanto para la política pública, como para las ciencias sociales, emerge un debate que 
correlaciona directamente la cualidad de vida en la vejez con el aumento de la capacidad de participación de las personas mayores. No obstante, cuando la OMS define las "actividades participativas", las indica como "participación en cuestiones sociales, educativas, económicas, culturales, recreativas, voluntarias, cívicas y hasta espirituales" (Beaskoetxea 2018:21), pero hace reducida mención de las actividades políticas (Beaskoetxea 2018:22).

Algunos autores justifican la baja tasa de participación política de la población mayor remitiendo a las dificultades de salud enfrentadas en las etapas avanzadas del ciclo vital (Serrat et al. 2017). En otra línea, Iacub y Arias (2010:26) consideran que esta baja participación es resultado de un proceso de pérdida de empoderamiento de los sujetos, particularmente para aquellos que dejan el mercado productivo. Esta pérdida de empoderamiento es multifactorial. Refiere, por ejemplo, a la disminución de la renta, a la marginación de actividades sociales, a la forma como el entorno social discrimina a los y las mayores, con base a imaginarios edadístas que asocian la vejez a la invalidez. Con todo, esta pérdida es diferencial entre diferentes géneros, lo que responde a la desigualdad de sobrecargas sociales acumuladas por estos distintos géneros a lo largo de la vida. Iacub y Arias explicitan que la integración de las y los adultos mayores a actividades sociales comunitarias constituye un elemento central para potenciar un empoderamiento político en la vejez:

La integración y la participación comunitarias han sido consideradas entre los factores que tienen mayor impacto sobre los niveles de calidad de vida en la vejez [...]. En definitiva, independientemente del fin por el cual hayan surgido, la creación, el sostenimiento y la participación en estas redes son a la vez causa y consecuencia del empoderamiento de los propios adultos mayores, en los que amplían su capacidad de participación política y social y los proyectan como grupo de presión y de poder (Iacub y Arias 2010:29-30).

Así, nuestro interés por las actividades de las mujeres mayores en Providencia alrededor de los talleres de bordado estaba respaldada por esta constatación de que, en este espacio, tendríamos un locus "etnográfico estratégicamente situado" (Marcus 1995:110) para observar procesos de negociación de las mujeres (de diálogo entre pares y con la municipalidad) del empoderamiento y de la marginación social por ellas enfrentados. Como explicitamos en la introducción, nuestro objetivo específico era comprender cómo dichas realidades afectaban la vida de las mujeres mayores de sectores de mediana y alta estratificación social, residentes en una comuna caracterizada por unas condiciones económicas bastante superiores a la media nacional chilena. Queríamos comprender en qué medida el envejecimiento provocaba, para ellas, procesos de renegociación de sus distinciones sociales y de los cuidados que entregaban a otros y a ellas mismas. Las distinciones y sus negociaciones son una clave para entender los procesos dialógicos de estas mujeres desde su lugar social específico.

Con distinciones, aludimos al debate de Bourdieu (2002) sobre las formas de diferenciación jugadas por los actores para establecer, simultáneamente, su ubicación en el campo social y su distancia con relación a los demás actores de este mismo campo ${ }^{6}$. Sabemos que estas estrategias no son neutrales -aun cuando se use un discurso naturalizador para justificarlas (Bourdieu 2002:67)-, que constituyen un sentido estético (Bourdieu 2002:53), que involucran la incorporación de estructuraciones sociales de mediana y larga duración, -los "condicionamientos de clase" (Bourdieu 2002:99), y que están, asimismo, vinculadas a la forma particular como los sujetos asumen corporalmente -en cuanto habitus- sus capitales culturales ${ }^{7}$, en la disputa por poder y posicionamiento.

\section{Providencia y el Taller}

Providencia tiene una población de 142.079 habitantes (INE 2017). Es una de las comunas más envejecidas de Chile: casi el $20 \%$ de sus habitantes tienen 60 años o más.

La comuna se diferencia de la mayoría de las demás del país por presentar una condición socioeconómica considerablemente más aventajada (Subsecretaría de Desarrollo Regional y Administrativo [SUBDERE] 2005). El diagnóstico realizado en 2013 para el Plan de Desarrollo Comunal (PLADECO) de Providencia indicaba que no había hogares bajo la línea de la pobreza en la comuna, aunque señalaba que eso no implicaba inexistencia de vulnerabilidades potenciales o necesidades básicas insatisfechas entre sectores de la población (Municipalidad de Providencia 2013). Esta particular condición -de tener una menor renta para su entorno local, pero no para el nacional-, dificulta a esta población el acceso a las redes estatales de protección social. La Encuesta de Caracterización Socioeconómica Nacional (CASEN) de 2015 apuntaba que la comuna contaba con un $0,7 \%$ de personas en condiciones de pobreza por ingresos, y un $4,4 \%$ de personas en condiciones de pobreza multidimensional, un índice bastante bajo para el contexto chileno (Gajardo 2015). Afirmaba, además, que 63,4\% de los adultos mayores en Providencia eran mujeres y que las personas mayores residentes en la comuna contaban, en su mayoría, con carreras profesionales universitarias 
y/o con postgrados. El 36,5\% de las personas mayores encuestadas respondieron haber trabajado al menos una hora durante la semana anterior a la entrevista en actividad no vinculada a los quehaceres del hogar. El $71,1 \%$ respondió que no aceptaría un trabajo, si es que se lo ofrecieran (MIDESO 2015).

La atención a la población mayor en Providencia queda a cargo del Departamento del Adulto Mayor, dependiente de la Dirección de Desarrollo Comunal de la Municipalidad. Este gestiona el "Programa Adulto Mejor", destinado a "promover la calidad de vida de los adultos mayores autovalentes y/o en riesgo de dependencia" (Municipalidad de Providencia 2017a).

Entre los principales espacios de los que dispone la comuna para la implementación de sus políticas hacia la tercera edad están los cuatro Centros Integrales del Adulto Mayor (CIAMs de Eliodoro Yáñez, Diego de Almagro, Juana de Arco y Santa Isabel) (Municipalidad de Providencia 2017b). En los CIAMs, la gestión de las actividades ocurre de forma coparticipativa: los usuarios se encargan de conformar los clubes comunitarios que se convierten en las células de organización de los talleres. Estos están destinados a prácticas artístico-recreativas (pintura, bordado, cerámica) y los clubes generan su identidad alrededor de estas (se forman, por ejemplo, "Clubs de Cerámica", "Clubs de Bordado") (Gonzálvez et al. 2019). Las mujeres mayores predominan entre las participantes.

El Centro Integral del Adulto Mayor ${ }^{8}$ donde realizamos nuestra investigación funciona en un gran inmueble de la Municipalidad, en un punto céntrico de la comuna. Además de la imponente casona de dos pisos donde funciona el CIAM, el recinto cobija otras construcciones que comparten un patio común. La infraestructura impresiona por su tamaño, por la diversidad de servicios comunitarios ofrecidos, por el cuidado de mantenimiento del lugar, de sus jardines $y$, también, por el agradable ambiente que sus espacios de esparcimiento proporcionan.

En la primera planta de la casona, a mano derecha, avistamos un mesón de recepción donde se encuentran los funcionarios administrativos, auxiliares de limpieza y un auxiliar de seguridad. A mano izquierda, encontramos una cómoda sala de estar con sillones y televisión. Al fondo, en el centro, la entrada para un amplio salón con escenario, donde se realizan talleres de teatro y bailes. En la pared del costado izquierdo de esta primera planta, se encuentran salas para talleres. En una de ellas -un recinto blanco, espacioso, muy iluminado, con una larga mesa, una pizarra, un piano de pared y cómodos asientos con vistas a los jardines del patio- se desarrolló, durante nuestro primer año de etnografía, el taller de bordado que frecuentamos.

Cuando iniciamos nuestro proceso etnográfico, en agosto de 2016, fuimos a conversar con dos figuras claves de la organización de los talleres. Una de ellas era la directora del CIAM, que era la responsable de coordinar todas las actividades que ocurrían allí (incluyendo las clases del taller de "tejido" ofrecidas de forma regular dos veces por semana) ${ }^{9}$. La otra era Gabriela (70 años), una residente de la comuna que desde hacía cinco años ofrecía voluntariamente -también dos veces por semana y de forma gratuita- un taller de técnicas de "bordado mexicano".

Estos talleres atraían dos perfiles diferenciados de asistentes. El primero, que era pagado, era frecuentado por mujeres con un más elevado perfil de renta, que llevaban años participando de estas clases, pero que estaban conectadas entre sí por redes personales previas al surgimiento de la actividad. Estas mujeres eran más activas políticamente en demandar de la administración del CIAM los derechos que, según entendían, les cabían como residentes de una comuna. Tanto la directora como Gabriela coincidían en etiquetar a estas mujeres como "el grupo de los derechos". Esta expresión irónica transmitía una apreciación de que estas demandas estaban íntimamente relacionadas con la defensa de un lugar de estatus "elevado" (Diario de Campo, 18.08.2016).

Por otro lado, un taller gratuito ofrecido por Gabriela, era frecuentado por señoras con un perfil económico mucho más heterogéneo, mediano o incluso bajo para el contexto de la comuna (Diario de Campo, 13.10.2016). Muchas de ellas ya dominaban la técnica que se enseñaba allí, pero seguían asistiendo a las clases porque eran el único espacio de esparcimiento al que podían acudir. Para algunas de estas mujeres el taller era una forma de trabajar en productos que podrían ser vendidos, complementando la renta mensual. Así, el servicio "voluntario" se configuraba como un espacio más inclusivo y diverso, mientras el taller contratado por la Municipalidad se configuraba como un espacio más "exclusivo", de mujeres con cierto posicionamiento económico, y empoderadas en la afirmación de sus derechos. Pese a esta diferencia, que es crucial en términos de la comprensión de los matices de distinción social que se entretejían en estos talleres, ambos tenían en común una frontera de género: no contaban con ningún hombre inscrito. Gabriela era una de las más activas integrantes del grupo de tejedoras, de hecho, era la líder de este grupo. Así, su acción como profesora del taller de bordado se enmarcaba también como parte de sus despliegues en cuanto miembro "destacado" del grupo "más exclusivo".

Fueron la directora y Gabriela quienes nos indicaron que debiéramos hacer etnografía en el taller comandado por la segunda, aduciendo que se trataba de un "mejor grupo". Contábamos con poco margen para cuestionar estas asignaciones en nuestra entrada al terreno, con lo cual aceptamos ser parte de este particular enredo 
de disputas que componía los talleres del CIAM. En las primeras incursiones junto a las mujeres del taller de bordados mexicanos el tema apareció. Las mujeres nos enunciaron que no había una "mala onda" explícita entre ellas y las del taller de tejidos; pero había una frontera socio-identitaria. Las del bordado se autoidentificaban como "más populares", mientras categorizaban a las otras como un "club de clase alta". Esta frontera incluía una clasificación de las otras señoras como más "formales" (aburridas), en contraposición a su autopercepción como más “desordenadas": dadas alasrisas, chistes, y distensiones del comportamiento. Una de las señoras que frecuentaba el taller más popular, doña Dolores nos confidenció que se había sumado al grupo porque todas sus compañeras allí eran "buenas para reír, alegres, conversadoras", como ella misma (Diario de Campo, 25.08.2016).

Entre 2016 y 2017 el taller de bordados mexicanos mantuvo un promedio de 30 mujeres inscritas, de las cuales al menos 20 conformaron el grupo de manera habitual ${ }^{10}$. Dos figuras femeninas desempeñaban roles importantes en este primer año: la propia Gabriela (70 años) y Antonia (79 años). Gabriela era autodidacta en lo que concierne a los oficios manuales que enseñaba. Muy activa, cumplía papeles protagónicos como articuladora de los dos talleres (de bordado y de tejido) ${ }^{11}$. Como profesora del taller de bordado, ejercía de manera más bien informal: iba enseñando de forma personalizada, en la medida en que sus atenciones eran solicitadas. No había una preparación estándar de los contenidos del curso. Así, la dinámica de las clases excedía las formalidades de la disciplina escolar más rígida y esto potenciaba que los talleres pudieran ofrecerse como un espacio de encuentro relacional. Para usar una metáfora muy apropiada, el aprendizaje del bordado se iba entretejiendo a la construcción de estas dinámicas de conversación e interacción y era indisociable de las mismas. Con todo, en algunas ocasiones, observamos que el trato de Gabriela con sus interlocutoras presentaba ciertas inclinaciones de firmeza (Diario de Campo, 03.08.2017) ${ }^{12}$. Gabriela se encargaba también de diversas acciones directivas: sus responsabilidades eran múltiples $^{13}$, así como sus militancias. Ella se posicionaba "dentro y fuera del taller" y era consciente del poder de gestión y negociación que tenía con las mujeres y con la municipalidad (Diario de Campo, 02.03.2017). Antonia, a su vez, ocupaba la función de "delegada". Se trataba de un puesto instituido por la administración del CIAM al que se atribuía la responsabilidad de transmitir las comunicaciones de la dirección del centro a los/ as asistentes de los talleres. Durante el primer año de nuestra etnografía, Antonia cumplió este rol acudiendo cada tres meses a las reuniones informativas organizadas por la dirección del CIAM.

A pesar de que no hubiera estatutos escritos que rigieran el taller, las mujeres habían establecido varias prácticas de coordinación colectiva, que cumplían con aspectos centrales de la gestión del grupo. Llevaban un listado de asistencias y se ponían en contacto con las compañeras que faltaban: habían acordado que tres faltas eliminaban a la persona del listado y se abría su cupo a una nueva integrante. Otro ejemplo se refiere al pago mensual de una cuota para costear las actividades de fin de año. Si bien este era de carácter voluntario, ellas habían consensuado que, una vez se empezaba a contribuir, no se podía dejar de hacerlo.

El CIAM, de su parte, disponía ciertas normas a las cuales ellas se adaptaban: los horarios y modos de uso de espacios, y la prohibición de llevar comidas o bebidas a las aulas. Para hacer frente a esta última regla, las señoras se organizaban para terminar las jornadas del taller tomando té en el casino del centro comunitario. El CIAM les facilitaba, entonces, el espacio de la cafetería y los insumos, y ellas pagaban precios más bajos que los de las cafeterías del entorno (Diario de Campo, 20.10.2016). En esta actividad, conocida popularmente en Chile como "tomar la once", las mujeres cerraban la jornada compartiendo, conversando entre sí. A menudo se juntaban los dos talleres, aunque las distinciones entre unas y otras no se desdibujaban (se sentaban separadamente). La organización usualmente estaba a cargo de Gabriela, quien delegaba en alguna de las señoras la tarea de anotar en una lista qué comería cada una.

Entre 2017 y 2018, el cambio de signo político en el gobierno municipal ocasionó la designación de un nuevo equipo directivo a cargo del CIAM. Esto redundó en una serie de modificaciones administrativas: entre ellas, la sorprendente cancelación del permiso de uso del aula para las actividades del taller de tejedoras ("del grupo de los derechos"). Fue Gabriela -el "puente" entre los grupos- quien medió la solución del problema, ofreciendo que el "popular" taller de bordado mexicano -que no tuvo sus actividades suspendidas- compartiera espacio con el "exclusivo" taller de tejidos. Fue en esta transición que los cursos sufrieron un empeoramiento de su espacio físico, pasando a un aula de la segunda planta que era menos luminosa y de menor que la que solían ocupar. Tenían, ahora, más gente y menos espacio.

\section{Entretejiendo Género y Cuidados}

Cuando les preguntábamos a las mujeres sobre el origen de su interés hacia el bordado, varias nos respondían situando sus narraciones en la infancia. Habían crecido en hogares donde otras mujeres bordaban, cosían y tejían: se trataría de un capital cultural incorporado -un habitus-, pero en clave de diferenciación de género. Un capital cultural femenino. Así, varias de ellas recordaron que sus 
madres les hacían ropa a ellas y a sus hermanos/as cuando pequeñas. Mientras ellas crecían, sus madres, abuelas o tías se encargaban de involucrarlas en este conocimiento específico: les entregaban los materiales e instrucciones para que comenzaran a bordar. Otras mujeres comentaron que aprendieron a bordar en las escuelas, donde estos saberes eran comprendidos como indispensables para las mujeres de sus generaciones.

Algunas nos relataron, además, que durante su infancia y adolescencia debieron lidiar con la valoración peyorativa de los hombres hacia estas actividades. Sus padres, abuelos y hermanos consideraban estas prácticas manuales como un despropósito. Romina (68 años) nos contó que su papá se oponía a que ella bordara, pues creía que las mujeres inteligentes debían estudiar y tener una profesión, no dedicarse a tejer. Temiendo la reacción de su papá, su mamá le enseñó a escondidas (Diario de Campo, 05.10.2017). Esta valoración de las figuras masculinas sobre las habilidades femeninas remite a un contexto específico de estratificación socioeconómica. La mala valoración masculina hacia estas "artes manuales" y también a la música o a la pintura en sus familias de origen se vinculaba al ímpeto de que las mujeres priorizaran el desarrollo de otras habilidades -principalmente las académicas-, que se comprendían como marcas de prestigio entre los sectores más elitistas de la sociedad santiaguina. No es una casualidad que las mujeres que nos hayan relatado esta experiencia estuvieran vinculadas al taller de tejidos, integrando el "grupo de los derechos".

Para las mujeres que frecuentaban el taller "popular" de bordados las manualidades fueron (en diferentes momentos de sus vidas) una estrategia de subsistencia y apoyo económico (Diario de Campo, 24.11.2016). Mientras las mujeres vinculadas al primer grupo crecieron en sectores urbanos y contaron con acceso a escuelas prestigiosas, muchas de las mujeres del segundo grupo habían migrado del campo a la ciudad, contando con acceso tardío o precario a la educación (generalmente en instituciones poco prestigiosas). Algunas de estas mujeres habían convertido el bordado y la costura en su oficio: estudiaron para ser operarias textiles en una escuela técnica, o para ser profesoras de corte y confección en la universidad.

Tanto en un caso como en el otro, retomar estas actividades en la vejez tenía significados trascendentes. A algunas, les permitía construir una conexión con un pasado que las situaba en cierto perfil laboral y de estratificación socioeconómico. A otras, les permitía ampliar sus conocimientos (aprendiendo nuevas puntadas o diseños) o, aún, conectarse a una actividad que les fue denegada, también debido a su posición en la estratificación socioeconómica, por una imposición masculina. La mayor parte de ellas coincidía, empero, en asumir el bordado como una forma femenina de entretención y pasatiempo: un ejercicio relajante, resguardado de las presiones por la productividad. Doña María Ignacia (74 años) nos contó que su marido le decía que "su problema" era que se dedicaba a hacer muchas cosas, como el taller de bordados, pero que "producía muy poco". Su respuesta al esposo fue decidida: "después de más de 38 años de puro producir, ahora puedo, finalmente, hacer cosas sin esa finalidad". (Diario de Campo, 05.10.2017).

En el taller, el acto de bordar estimulaba en las mujeres rememoraciones. Algunas hablaban de su infancia, retomando en estas narraciones el momento en que aprendieron a bordar. Otras reflexionaban sobre cómo las manualidades eran una forma de dar materialidad al cuidado de amigos y familiares: las piezas tejidas y bordadas serían regaladas o eran objetos hechos a medida para suplir una necesidad de una nieta o nieto, de una hija o hijo, de sus sobrinos.

En cierta ocasión, Doña Inés (91 años) aprovechó la pausa de la clase para apreciar cómo iba quedando su bordado. En este gesto de mirar y reflexionar sobre la materialidad de su obra, nos comentó que ya estaba cansada y que lo quería terminar pronto. Le instamos a no desanimar, que había un claro progreso con relación a la última vez que lo había trabajado en el taller. Ella nos dijo, entonces, que su apuro en terminar se debía a que, por su edad, esto iba a ser lo último que iba a poder bordar. No quería "irse" dejando el trabajo a medias. (Diario de Campo, 27.10.2016). Aquí, la materialidad de la obra terminada significaba para doña Inés el cierre de su propio ciclo vital: el bordado le ayudaba a asimilar, en la placidez de las florecitas sobre el tejido, el cierre de este otro ciclo, que ella misma encarnaba y del cual tenía que aprender a despedirse. El bordado era, entonces, la condensación de la historia de toda una vida. Doña Inés había grabado, simbólica y metonímicamente, su propia vida en el tejido.

El taller constituía un espacio donde las mujeres negociaban, asimilaban y compartían sus relaciones con los mandatos del cuidado: de sí mismas y de los demás. Las mujeres que contaban con una mejor situación socioeconómica relataban relaciones con los familiares descendientes en las cuales ellas eran receptoras de cuidados. Frecuentemente, cuando hablaban de la relación con sus nietos y nietas, decían que su función era "chochearlos". La expresión significa, en Chile, hacerles cariños y mimos. Se refiere a la expresión del afecto, pero sin implicar en esta expresión actividades que sean vitales para el otro. Doña Inés (91 años) nos decía, por ejemplo, que no cuidaba, sino que "chocheaba" con sus nietos y bisnietos, generalmente los domingos. Sus hijos administraban sus recursos económicos (además de la pensión, los arriendos de algunas propiedades) y se ocupaban de que no le faltara nada (Diario de Campo, 18.08.2016). Otras mujeres -Pamela (68 años), 
Carmen (75 años) y Antonia (79 años)- relataron que se encargaron de los cuidados de sus padres y madres cuando ellos se hicieron mayores, pero que lo hicieron con tranquilidad: disponían de recursos para contratar asistencia médica, de enfermeras y/o cuidadoras, y para las medicaciones (Diario de Campo, 29.09.2016).

En contraste, las mujeres con menores ingresos relataban que ejercían papeles cruciales en el cuidado de los nietos y nietas e, incluso, de hijas e hijos, ocupándose de tareas de reproducción del hogar (cocinar, limpiar, comprar). Doña Dolores, por ejemplo, vivía en el mismo edificio que una de sus hijas, y cuidaba a su nieto en la semana (su hija le remuneraba por ello) e incluso de un bisnieto. Cuidaba, además, a su marido que sufría de enfermedades crónicas y dolencias variadas. Todo esto le complicaba exponencialmente la vida debido a sus propias enfermedades: ella también requería de cuidados y no podía contar con nadie para ello. La delicada situación económica de Dolores suscitó que algunas mujeres, comandadas por Gabriela, decidieran hacer una rifa para recaudar fondos y ayudarla. El tema devino en un conflicto, puesto que algunas señoras entendían que este tipo de acciones no eran pertinentes para aquel espacio: los talleres eran un lugar para mujeres "bien paradas" económicamente, y no para "asistencia social" (Diario de Campo, 23.09.2017).

En diferentes casos, observamos que estas mujeres postergaban su propio bienestar para asumir estas responsabilidades. Ejemplo de ello fue Thelma (de unos 70 años), a quien vimos reincorporarse al taller tras meses sin poder acudir a las clases, dado que cuidaba intensivamente de su madre enferma (de 99 años). En el día de su reincorporación a las clases, nos contó que llevaba prácticamente cuatro meses sin poder salir de la casa y sin tener tiempo para siquiera tomar sus palillos de tejer. La vimos, este día, muy cansada, con la mirada perdida. Le había tocado una muy mala noche: su mamá se despertó de madrugada con dolores y ella tuvo que atenderla. Aunque intentó, aquel día, avanzar en un tejido, comentó a las compañeras de curso que sencillamente se le había olvidado cómo hacer los puntos (Diario de Campo, 29.09.2016).

\section{La Política de las Distinciones}

El posicionamiento político de las mujeres constituía un elemento estructurante de sus intercambios en el taller. Esta dimensión puede ser rastreada en por lo menos tres elementos.

El primero refiere al interés de las señoras por institucionalizar su vínculo en el taller de bordado mexicano, que se expresó muy fuertemente en el primer año de nuestras observaciones. Doña Antonia nos comentó, en el segundo mes de nuestras observaciones, que ellas habían resuelto constituirse oficialmente como un "club social y comunitario" de bordado. Así, solicitaron su registro en la municipalidad, requisito necesario para tramitar la personalidad jurídica del club. El personal de la municipalidad acudiría al taller para ayudarlas con el estatuto del club y realizar la asamblea constitutiva, recopilándose las firmas legalmente requeridas de las socias. Doña Gabriela pidió, entonces, que dispusiéramos la sala en una gran mesa grande y que todas las señoras se sentaran a su alrededor. Las mujeres debían dejar al lado sus trabajos y poner atención a las conversaciones y votaciones. Dos funcionarios municipales junto con Gabriela dirigieron esta junta de constitución. La lectura de los estatutos propuestos duró casi una hora. Luego, tuvieron que firmar los libros y pasar a elegir a la directiva provisoria, para terminar con una foto grupal, testimonio de que el proceso se hizo correctamente (Diario de Campo, 13.10.2016).

Le decisión de constituirse formalmente como club era de carácter político: una estrategia para permitirles una representación social legítima y, a través de esta, resolver asuntos prácticos como la articulación de demandas frente a instituciones del gobierno y el financiamiento de actividades. Gabriela recalcó, en diversas ocasiones, que esta formalización les permitiría sumarse a instancias de organización representativa, como la Unión Comunal de Adultos Mayores, o postular a fondos concursables del Servicio Nacional del Adulto Mayor (Diario de Campo, 05.10.2017).

Después de este primer paso, el proceso se fue haciendo engorroso: a las mujeres les costaba comprender todos los requisitos legales, plazos y acciones que cumplir. Casi un año después de la reunión constitutiva, en septiembre de 2017, volvieron a poner el tema sobre la mesa para avanzar en la designación de un Tribunal Calificador de Elecciones y un directorio para el club. Era tarde. Según explicó Antonia (79 años), se habían pasado los plazos y la inscripción municipal del club había caducado sin terminar de formalizarse (Diario de Campo, 07.09.2017). Con la fusión del taller de bordado con el de tejidos, el tema de la constitución del club se convirtió en un oxímoron. Las mujeres de los tejidos no estaban de acuerdo con este tipo de iniciativas: no tenían interés en llevarlas adelante. Esto habla, una vez más, de una distinción entre posicionamiento frente a la política para aquellas mujeres con más o menos recursos.

Un segundo aspecto se refiere a que diversas de las instancias dialógicas proporcionadas por los talleres también constituían espacios donde las mujeres negociaban sus reflexiones con relación a su ejercicio de la ciudadanía. En las "onces" al final de los talleres, algunos conflictos acerca de sus derechos eran puestos sobre la mesa. En cierta ocasión, la huelga de los funcionarios del centro municipal tensionó la organización de la merienda. Una de ellas había llevado 
una torta como regalo al grupo y para que compartieran algo de comer en el caso de que la cafetería no funcionara por el paro. Gabriela aprovechó, inmediatamente al final de la clase, para preguntar quiénes tomarían té ese día. Dijo que, además de la torta, la directora del centro había garantizado un té y 1/2 sándwich para cada una. Estos saldrían por mil pesos.

A esta oferta, Doña Julia (71 años) contestó que quería sólo el té y no el pan. Doña Pilar le dijo que de todos modos le cobrarían el valor integral, al que Julia dijo que no le importaba, que no quería pan porque no le gustaban los sándwiches que hacían. Entre doña Corina y doña Pilar le explicaron que daba lo mismo que no quisiera, que podría regalarlo a alguien más, que la idea era compartir, que eran sólo mil pesos, y Gabriela añadió -pidiendo silencio para que todas escucharan-que "ellas también tenían que aportar un poco", porque el CIAM les daba la garantía de que podían tomar el té allí, que ellas "tenían que cooperar". Doña Julia se paró frente a este enunciado. Le molestó profundamente que se diera a entender que el té era de algún modo un beneficio que les daba la municipalidad. Doña Julia expresó, entonces, que era un servicio por el que pagaban, que no era un regalo, que la iniciativa de tomar té juntas era de ellas, que nadie debiera estar obligado a participar como forma de agradecimiento al CIAM o a la municipalidad por "dejarlas" estar allí. Ellas tenían el derecho como ciudadanas, decía. (Diario de Campo, 10.08.2017).

En otras ocasiones, el espacio del taller era usado como locus de enunciación del derecho de reconocimiento social por parte de estas mujeres y ellas abogaban por su demanda por ser tomadas como ciudadanas que pueden aportar por sus capacidades. Las capacidades, decían, eran más relevantes que la edad. Esta demanda emergió, por ejemplo, en las conversaciones de las mujeres sobre las charlas de salud que la municipalidad ofrecía en el CIAM. Tras una de ellas, sobre memoria y demencia, María Ignacia comentó que algunas mujeres salieron del evento visiblemente irritadas: la información les fue entregada "como si fuésemos personas retrasadas". Ellas no estaban de acuerdo con recibir de la municipalidad un trato infantilizado (Diario de Campo, 07.09.2017).

Así, el espacio que ellas articulaban en los talleres también les permitía construir de forma auto afirmativa -para ellas y entre ellas- enunciados sobre el valor político y cultural de las mujeres mayores. Reiteraban en sus conversaciones los "años de servicio" entregados por ellas para la construcción de sus entornos sociales y reivindicaban políticas afirmativas que les permitieran ocupar, como ciudadanas, los espacios públicos.

Uno de los temas tratados en estas conversaciones decía relación con la "Marcha de los Bastones", manifestación política que llevó muchos adultos y adultas mayores a protestar por las calles de Santiago en diversas ocasiones en 2017, reivindicando de la entonces presidenta (Michelle Bachellet) una solución para los serios problemas del sistema privatizado de pensiones en Chile, asi como la consecución de derechos de movilidad en el transporte público (pasaje reducido) para la población adulta mayor. En estas conversaciones, las mujeres posicionaban su indignación frente a la negativa del gobierno en atender estas demandas. Una de ellas preguntó, abiertamente, por qué el Estado consideraba que no había recursos para atender a las personas mayores, "que somos quienes construimos este país" (Diario de Campo, 28.09.2017).

Asimismo, el taller también servía a las mujeres como espacio de articulación de su posicionamiento y demandas respecto a la gestión municipal. En ocasión del cambio de administración del CIAM, entre el primer y segundo año de nuestra investigación, vimos cómo las mujeres enunciaban su apreciación sobre la nueva directora del centro, a quien no encontraban preparada para el cargo. Reprochaban, además, su involucramiento con casos de corrupción (Diario de Campo, 19.01.2017). También se discutieron en el taller las decisiones de la nueva alcaldesa, afiliada a un partido de derecha, de cerrar el Programa Municipal de Adulto Mayor Autovalente y otros servicios y programas de salud. Discutieron, entonces, tomar una medida concreta: mandar una carta a la alcaldesa, a los medios de comunicación y a otras autoridades pertinentes para impedir el cierre de estos programas, reclamando, particularmente, que esto iba en contra de las propuestas de campaña (que había anunciado que los y las adultas mayores serían prioridad de la gestión) (Diario de Campo, 22.12.2016).

Finalmente, el taller era un lugar de expresión y construcción de acciones políticas que las posicionaban frente a partidos políticos y movimientos militantes. Algunas de las sesiones terminaban antes porque las mujeres iban en bloque a eventos políticos, como la finalización de la candidatura de una representante de un partido de izquierda que postulaba a alcaldesa, y a quien apoyaban masivamente (Diario de Campo, 20.10.2016).

Por otro lado, las mujeres demostraron su capacidad de marcar límites a la intervención política que atravesaba el espacio del taller. En las campañas políticas, los y las candidatas a cargos ejecutivos las visitaban para pedir su voto y sacarse fotos con ellas. En una de estas ocasiones, la entrada del asesor de un candidato fue tan sorpresiva e imprudente que Gabriela lo paró apenas él terminó de anunciar que el candidato las quería invitar a un almuerzo para contarles sobre sus propuestas. Interrumpiéndole la intromisión, Gabriela lo saludó y le dijo que ella era la profesora del taller y que no estaba al tanto de que él las iba a visitar. Él se disculpó, aunque se lo tomó con mucha gracia, e 
insistió en que todas estaban cordialmente invitadas a la actividad, pero que él necesitaba confirmación para poder hacer la reserva en el restaurante. Por lo mismo, propuso que la profesora hiciera una lista de las interesadas y se la enviara a él por whatsapp. En tono más enfático, Gabriela le respondió directamente que no lo haría. Que su modo de invadir el taller no era correcto, que ella era la profesora y que se hacía cargo de organizar actividades propias del taller, no actividades externas. Le dijo, además, que no quería verse involucrada en la campaña del candidato al que él representaba y que, por lo mismo, siendo aquella una invitación a una actividad voluntaria, que ella no iba a participar, ni gestionar la participación de nadie más.

En la secuencia, Julia (71 años) aprovechó para preguntarle al asesor de qué partido era su candidato. Cuando él contestó que era de derecha, varias señoras dejaron de ponerle atención y volvieron a sus bordados. Doña Julia (militante activa desde su juventud en un partido tradicional de izquierda) se entretuvo molestándolo un rato. El asesor la molestaba de vuelta, insistiendo en que fuera a conocer al candidato y a hablar con él, quizás así "se convencía" y terminaba votando por la derecha por primera vez. Julia le contestó vivamente: "a estas alturas, mijito, yo ya tengo claro lo que creo y no me van a hacer cambiar de opinión con un almuerzo. Tú no te imaginas con quién estás hablando". Julia le explicó, además, que esta "picardía" con la que él llegaba a invitarlas y tratar de "convertirlas" era un recurso muy antiguo. Ella lo conocía mucho mejor que él (Diario de Campo, 28.09.2017).

\section{Consideraciones Finales}

A través de los datos arrojados por nuestra etnografía, concluimos que los talleres de bordado y tejido constituían un espacio femenino de construcción de posicionamiento político y esto se vinculaba a la dimensión coparticipativa que resulta de estas prácticas manuales. Bordar, tejer y coser son prácticas extensamente asociadas a los mandatos de género femeninos (Phillips 1995:89). Diversos autores vienen observando que, de forma transhistórica y transcultural (Agosín 2014) -en diferentes periodos y en los más diversos rincones, sociedades y comunidades- tejer y bordar han representado (a la vez que han potenciado), enunciados políticos (y de formas contrahegemónicas de la memoria) en claves femeninas (Agosín 2008:16).

Diversas antropólogas feministas vienen desde hace décadas debatiendo sobre la separación bipolar entre público y privado, la cual se reproduce en la división dicotómica entre lo doméstico y lo público (González y Acosta 2015; Gregorio y Alcázar 2014; Lamas 1999; Segato 2013,2016). Esta visión cartesiana promueve la despolitización del género femenino, dado que, en las sociedades patriarcales (predominantes en el mundo), las mujeres han sido simbólicamente recluidas a la esfera de lo doméstico, habiendo esta esfera sido desposeída de su carácter político inherente (Segato 2013:72-74). Siguiendo a Segato (2016:25), la recuperación de la dimensión política de las actividades desarrolladas históricamente por las mujeres en el ámbito privado (como, por ejemplo, los cuidados y los trabajos de reproducción social), es paso primordial para una recuperación crítica de las dimensiones sistémicas (no dicotómicas, no bipolares) de la forma femenina de hacer política. Esto, que Segato (2016:25) denomina desde la antropología crítica feminista como una "domesticación de la política”, es precisamente la apuesta que sedimentó el trabajo llevado a cabo en nuestro estudio.

Así, el hecho de que llegáramos a la dimensión política de las mujeres en un estudio en que nos preguntábamos por los cuidados no es ni una casualidad, ni una miopía, ni mucho menos una distorsión resultante de nuestra incapacidad científica de establecer "buenos focos" (léase, "focos androcéntricos") para nuestro estudio. Si llegamos a la dimensión política de la experiencia de las mujeres a través del cuidado, lo hicimos porque el cuidado realizado grupalmente por las mujeres en el espacio social del taller significa una experiencia política y las articula en cuanto sujetos políticos. Así, nuestro estudio concluye, como hicieron muchas feministas tan lúcidas antes de nosotras, que los cuidados son políticos.

Varias de nuestras observaciones a lo largo del proceso etnográfico confirman estas afirmaciones para el caso del taller de Providencia. Rescataremos cinco de estos aspectos.

1. La constitución de estas técnicas manuales como un mandato femenino nos quedaba patente en el hecho de que la mayoría de las mujeres que asistía a las clases ya había aprendido estas técnicas con anterioridad, desde sus familias.

2. Bordar y tejer constituía un espacio autorreflexivo para ellas: les abría la posibilidad de reconsiderar la "utilidad" de las actividades que realizan, estableciendo interpretaciones propias sobre el significado de la práctica de las manualidades en las distintas etapas de sus ciclos vitales. Para las mujeres de diferentes orígenes y posiciones, bordar significaba un ejercicio de sentido femenino, reconectado con temporalidades contrahegemónicas (no necesariamente afines a las lógicas del mundo productivo).

3. Observamos que la producción de estas materialidades desde las manos de las mujeres integraba para ellas un sistema de prestaciones totales (en términos antropológicos clásicos). Como definió Comas (2017), el cuidado constituye también 
un sistema de reciprocidad intermediado por la obligación de dar, recibir y retribuir: y los elementos bordados y tejidos por las mujeres eran integrados a esta cadena del "don", como materialidades que consustanciaban estos intercambios. Eran regalos para la gente a quienes ellas cuidaban y que les cuidaban a ellas también.

4. Vimos que algunas mujeres usaban el espacio del taller y las manualidades en él desarrolladas para afrontar un desafío venidero y con profundas implicaciones de carácter psicosocial: significar y asimilar la proximidad de la muerte.

5. Constatamos que el taller constituía un espacio centralmente femenino también porque, en él, las mujeres negociaban, asimilaban y compartían sus relaciones con los mandatos del cuidado: de sí mismas y de los demás. Observamos que la estratificación socioeconómica en la que se situaban era un elemento de distinción para la configuración de los cuidados en la experiencia de la vejez. Las mujeres con mejores posiciones económicas eran cuidadas por sus familiares, mientras aquellas que contaban con peores condiciones seguían siendo pilares de los cuidados familiares (incluso sin tener las condiciones económicas y de salud para tal). Nuestra etnografía da indicios, entonces, de que incluso en aquellos sectores sociales con más recursos, la vejez sigue implicando una sobrecarga de cuidados para un número relevante de mujeres y esto significa un empeoramiento en sus condiciones de salud, económicas, psicológicas y sociales en sus ciclos vitales más avanzados.
Nuestro estudio evidencia que nuestras compañeras de taller son conscientes de ocupar un espacio distinto al de otras comunas de la ciudad y lo enuncian, aunque también reconocen que hay diversidad en la vejez en Providencia. Esta diversidad se manifiesta en las relaciones y posicionamientos en el propio taller, pero ellas usan este espacio para poner estos conflictos sobre la mesa. Así, estas mujeres mantienen y defienden formas activas de ciudadanía desde reflexiones críticas, pero también desde el involucramiento en causas socialmente visibles, como la "Marcha de los Bastones". El involucramiento político que constatamos entre estas señoras permite deconstruir ciertas perspectivas analíticas y distorsiones edadístas en las ciencias sociales, según las cuales las mujeres mayores constituyen sujetos sin agencia. Los talleres representan un espacio donde ellas pueden desarrollar ideas sobre su participación democrática y, al mismo tiempo, ejercer y optimizar los capitales sociales, culturales y políticos que mantienen y que constituyen sus recursos de distinción social.

Agradecimientos: Agradecemos a la Comisión Nacional de Investigación Científica y Tecnológica de Chile (CONICYT) que financia este estudio a través del proyecto Fondecyt 1160683: "Ser Mujer Mayor en Santiago de Chile: Organización Social de los Cuidados, Feminización del Envejecimiento y Desigualdades acumuladas", dirigido por Herminia Gonzálvez Torralbo y codirigido por Menara Guizardi. Agradecemos, afectuosamente la participación en esta investigación a cada una de las mujeres del Taller de bordados, quienes por largo tiempo compartieron con nosotras sus vivencias sobre el proceso de envejecer.

\section{Referencias Citadas}

Abu-Lughod, L. 1990. Can there be a feminist ethnography? Women \& Performance: A journal of Feminist Theory 5 (1):7-27.

Agosín, M. 2008. Tapestries of Hope, Threads of Love: The Arpillera Movement in Chile. Rowman \& Littlefield, Lanham.

Agosín, M. (ed.) 2014. Stitching Resistance: Women, Creativity, and Fiber Arts. Solis Press, Kent.

Aguirre, R. 2007. Familias como proveedoras de servicios de cuidados. En Género y Cohesión Social, editado por J. Astelarra, pp.1-10. Fundación Carolina, Madrid.

Aranibar, P. 2001. Acercamiento Conceptual a la Situación del Adulto Mayor en América Latina. CEPAL, Santiago.

Arnold-Cathalifaud, M., D. Thumala; A. Urquiza y A. Ojeda 2007. La vejez desde la mirada de los jóvenes chilenos: estudio exploratorio. Última Década 27:75-91.

Aronson, J. 1992. Women's sense of responsibility for the care of old people. Gender \& Society 6 (1):8-29.
Arquiola, E. 1995. La Vejez a Debate: Análisis Histórico de la Situación Sociosanitaria de la Vejez en la Actualidad. CSIC, Madrid.

Arriagada, I. 2007. Familias y Políticas Públicas en América Latina. Una Historia de Desencuentros. CEPAL-UNFPA, Santiago.

Arriagada, I. 2010. La crisis de cuidado en Chile. Revista de Ciencias Sociales 23 (27):58-67.

Arriagada, I. 2011. La Organización Social de los Cuidados y Vulneración de Derechos en Chile. ONU Mujer, Santiago.

Beaskoetxea, I.Z. 2018. Envejecimiento activo y participación política. Aula Abierta 47 (1):21-28.

Behar, R. 1995. Introduction: Out of Exile. En Women Writing Culture, editado por R. Behar y D. Gordon, pp.1-32. University of California Press, Berkeley.

Bell, D. 1993. Introduction: The context. En Gendered Fields. Women, Men and Ethnography, editado por D. Bell, P. Caplan y W.J. Karim, pp.1-13. Routledge, Londres, Nueva York. 
Berreman, G.D. 1966. Anemic and emetic analyses in social anthropology. American Anthropologist 68 (2):346-354.

Bourdieu, P. 2002. La Distinción. Criterios y Bases Sociales del Gusto. Taurus, Ciudad de México.

Bourdieu, P. 2011. Las Estrategias de la Reproducción Social. Siglo Veintiuno Editores, Buenos Aires.

Butler, R. 1969. Age-ism: Another form of bigotry. The Gerontologist 9 (4):243-246.

Calasanti, T., K.F. Slevin y N. King 2006. Ageism and Feminism: From "Et Cetera" to Center. NWSA Journal 18 (1):13-30.

Ministerio de Desarrollo Social [MIDESO] 2013. Encuesta de Caracterización Socioeconómica Nacional 2013. Una Medición de la Pobreza Moderna y Transparente para Chile. Ministerio de Desarrollo Social, Santiago.

Ministerio de Desarrollo Social [MIDESO] 2015. Encuesta de Caracterización Socioeconómica Nacional 2015. Ampliando la Mirada sobre la Pobreza y la Desigualdad. Ministerio de Desarrollo Social, Santiago.

Comas, D. 2017. El don y la reciprocidad tienen género: las bases morales de los cuidados. QUADERNS-E 22 (2):17-32.

Cummings, E. y W.E. Henry 1961. Growing Old. Basic, New York.

Del Valle, A.H. 2013. Bienestar, familia y problemas de cuidados en América Latina. Emancipação 13 (3):43-82.

Dietz, G. 2011. Hacia una etnografía doblemente reflexiva: una propuesta desde la antropología de la interculturalidad. AIBR $6(1): 4-26$

Duffy, M. 2011. Making care count. A century of gender, race and paid care work. Rutgers University Press, New Jersey.

Dundes, A. 1962. From etic to emic units in the structural study of folktales. The Journal of American Folklore 75 (296):95-105.

England, P. 2005. Emerging theories of care work. Annual Review of Sociology 31:381-399.

Ezquerra, S. 2012. Sobre viejas y nuevas gestiones de la crisis o el retorno de las mujeres al hogar. Viento Sur 121:87-95.

Fernández, J.M.F y S y Kehl 2001. La construcción social de la vejez. Cuadernos de Trabajo Social (14):125-161.

Filgueira, F. 2009. El Desarrollo Maniatado en América Latina. CLACSO, Buenos Aires.

Flores, E., E. Rivas y F. Seguel 2012. Nivel de sobrecarga en el desempeño del rol del cuidador familiar de adulto mayor con dependencia severa. Ciencia y Enfermería 28 (1):29-41.

Forttes, P. 2016. La Dependencia y Apoyo a los Cuidados, un Asunto de Derechos Humanos. SENAMA, Santiago.

Gajardo, S. 2015. Pobreza y Distribución del Ingreso en la Región Metropolitana de Santiago: Resultados Encuesta Casen 2015. Seremi de Desarrollo Social RM, Santiago.

Gallardo-Peralta, L., A. Cuadra-Peralta, X. Cámara-Rojo, B. Gaspar-Delpino y R. Sánchez-Lillo 2017. Validación del inventario de envejecimiento exitoso en personas mayores chilenas. Revista Médica de Chile 145:172-180.

Gallardo-Peralta, L.P., E. Sánchez-Moreno, A. Arias-Astray y A. Barrón López-de-Roda 2015. Elementos estructurales de la red social, fuentes de apoyo funcional, reciprocidad, apoyo comunitario y depresión en personas mayores en Chile. Anales de Psicología 31:1018-1029.
Ganga, F., M.A. Piñones, D. González y F. Rebagialti 2016. Rol del Estado frente al envejecimiento de la población: el caso de Chile. Convergencia 23 (71):175-200.

Gibson, D. 1996. Broken down by age and gender "the problem of old women" redefined. Gender and Society 10(4):433-448.

Giménez, D. 2004. Género, previsión y ciudadanía social en América Latina. En Los Sistemas de Pensiones en América Latina: un Análisis de Género, coordinado por F. Marco, pp.99152. CEPAL, Santiago.

Ginn, J. y S. Arber 1991. Gender, class and income inequalities in later life. The British Journal of Sociology 42 (3):369-396.

Glenn, E.N. 2010. Forced to Care: Coercion and Caregiving in America. Harvard University Press, Cambridge.

Gonzálvez, H. 2017. Ser mujer mayor en Santiago de Chile: feminización de los cuidados en la vejez y desigualdades acumuladas. En Malestar Social y Desigualdades en Chile, editado por A. Vera, pp.173-194. Ediciones UAH, Santiago.

Gonzálvez, H. 2018. Género, cuidados y vejez: mujeres "en el medio" del trabajo remunerado y del trabajo de cuidado en Santiago de Chile. Revista Prisma Social 21:194-218.

Gonzálvez,H. y E. Acosta 2015. Cruzar las fronteras desde los cuidados: la migración transnacional más allá de las dicotomías analíticas. En Las Fronteras del Transnacionalismo. Limites y Desbordes de la Experiencia Migrante en el Centro y Norte de Chile, editado por M. Guizardi, pp.126-150. Ocho Libros, Santiago.

Gonzálvez, H., M. Guizardi, A. Ramírez y C. Cano 2019. El club como trinchera. Una etnografía sobre cuidados comunitarios entre mujeres mayores en Independencia (Chile). Revista de Antropología Social 28 (1):137-166.

Gregorio, C. y A. Alcázar 2014. Trabajo de campo en contextos racializados y sexualizados. Cuando la decolonialidad se inscribe en nuestros cuerpos. Gazeta de Antropología 30 (3):1-16.

Harris, M. 1976. History and significance of the emic/etic distinction. Annual Review of Anthropology 5 (1):329-350.

Huenchuán, S. 2014. “QQué más puedo esperar a mi edad?”. Cuidado, derechos de las personas mayores y obligaciones del Estado. En Autonomía y Dignidad en la Vejez: Teoría y Práctica en Políticas de Derechos de las Personas Mayores, editado por S. Huenchuán y R. Rodríguez, pp.153-168. CEPAL, Santiago.

Hutheesing, O.K. 1993. Facework of a female elder in a Lisu field, Thailand. En Gendered Fields. Women, Men and Ethnography, editado por D. Bell, P. Caplan y W. Karim, pp.93-102. Routlegde, Londres.

Iacub, R. y C.J. Arias 2010. El empoderamiento en la vejez. Journal of Behavior, Health \& Social Issues 2 (2):25-32.

Instituto Nacional de Estadísticas [INE] 2017. Resultado de Población por Sexo y Edad. INE, Santiago.

Izquierdo, M.J. 2003. Del Sexismo y la Mercantilización del Cuidado a su Socialización: Hacia una Política Democrática del Cuidado. Emakunde, Barcelona.

Jelin, E. y P. Vila 2018. ¿Veinte años no es nada? (Volver sobre) fotografías y cotidianidad popular en los ochenta. En Podría Ser Yo (reedición revisitada), editado por A. Triquell, pp. 21-54. Asunción, Buenos Aires.

Johnson-Hanks, J. 2002. On the limits of life stages in ethnography: toward a theory of vital conjunctures. American Anthropologist 104 (3):865-880. 
Lamas, M. 1999. Usos, dificultades y posibilidades de la categoría género. Papeles de Población 21:148-178.

Levy, J. 1988. Intersections of gender and aging. The Sociological Quarterly 29 (4):479-486.

Lins de Barros, M.M. 2006. Trajetória dos estudos de velhice no Brasil. Sociologia, Problemas e Práticas 52:109-132.

Manzo, E.G. 2010. Las teorías sociológicas de Pierre Bourdieu y Norbert Elias: los conceptos de campo social y habitus. Estudios Sociológicos 28 (83):383-409.

Marco, F. 2004. Rasgos generales de los sistemas previsionales de capitalización individual y de sus contextos laborales y demográficos. En Los Sistemas de Pensiones en América Latina: Un Análisis de Género, coordinado por F. Marco, pp. 31-60. CEPAL, Santiago.

Marcus, G.E. 1995. Ethnography in/of the world system: The emergence of multi-sited ethnography. Annual Review of Anthropology 24 (1):95-117.

Marshall, L. 2006. Aging: A feminist issue. NWSA Journal 18 (1):7-13.

McNamara, P. 2009. Feminist ethnography: Storytelling that makes a difference. Qualitative Social Work 8 (2):161-177.

Menéndez, J., A. Guevara, N. Arcia, E.M. León, C. Marín y J.C. Alfonso 2005. Enfermedades crónicas y limitación funcional en adultos mayores: estudio comparativo en siete ciudades de América Latina y el Caribe. Revista Panamericana de Salud Pública 17:353-361.

Montero, I. y M. Bedmar 2010. Ocio, tiempo libre y voluntariado en personas mayores. Polis 26:1-17.

Morenos, D. y A.I. Corregidor 2010. Urbanismo, espacio público y personas mayores: hacia la amabilidad de las formas. Revista de Terapia Ocupacional de Galicia 3:232-254

Municipalidad de Providencia 2017a. Programa del Adulto Mejor http://www.providencia.cl/programa-adulto-mejor (26 julio 2018).

Municipalidad de Providencia 2017b. Centro del Adulto Mayor Santa Isabel http://providencia.cl/infante1415/item/187-centroadulto-mayor-santa-isabel-ciam (20 marzo 2018).

Naples, N.A. 2013. Feminism and Method: Ethnography, Discourse Analysis, and Activist Research. Routledge, New York

Nazar, G. y C. Figueroa 2015. Creencias estereotípicas sobre el desempeño laboral de trabajadores mayores en Chile. Psicoperspectivas. Individuo y sociedad 14 (1):114-125.

Organización para la Cooperación y el Desarrollo Económicos [OECD] 2015. Pensions at a Glance 2015: OECD and G20 Indicators. OECD, Paris.

Organización Internacional del Trabajo [OIT] 2009. Envejecimiento de la población: ¿quién se encarga del cuidado? Notas OIT 8:1-4

Organización Mundial de la Salud [OMS] 2016. World Health Statistics 2016: Monitoring Health for the SDGs. OMS, Ginebra

Organización Mundial de la Salud [OMS] 2002. Envejecimiento activo: un marco político. Revista Española de Geriatría y Gerontología 37 (2):74-105.

Osorio, P. 2006. La longevidad: más allá de la biología. Aspectos socioculturales. Papeles del CEIC 22:1-28.

Osorio, P. 2007. Construcción social de la vejez y expectativas ante la jubilación en mujeres chilenas. Revista Universum 22 (2):202-220.
Osorio, P., I.N. Luco y S.B. Barrales 2018. Social and cultural perspectives on the self-care and care for nonagenarians and centenarians in rural areas in Chile. Antipoda 31:45-63

Pérez-Orózco, A. 2006. Amenaza tormenta: la crisis de los cuidados y la reorganización del sistema económico. Revista de Economía Crítica 5:7-37.

Phillips, B.D. 1995. Women's studies in the core curriculum: Using women's textile work to teach women's studies and feminist theory. Feminist Teacher 9 (2):89-92.

Programa de Naciones Unidas para el Desarrollo [PNUD] 2017. Desiguales. Orígenes, Cambios y Desafíos de la Brecha Social en Chile. Uqbar Editores, Santiago.

Prieto, D., D. Herranz y P. Rodríguez 2015. Envejecer sin ser Mayor. Nuevos Roles en la Participación Social en la Edad de la Jubilación. Fundación Pilares, Madrid.

Retamales, H.N. 2018. ¿Hay algún afuera del trabajo? Biomedicina, trabajo y vejez en Chile. Sociológica 33 (94):203-234.

Rosaldo, M. y L. Lamphere (eds.) 1974. Woman, Culture, and Society. Stanford University Press, Stanford.

Rosenthal, E. R. 1990. Women and varieties of ageism. Journal of Women \& Aging 2(2):1-6.

Salverda, T. y J. Abbkink2013. Introduction. An Anthropological Perspective on Elite Power and the Cultural Politics of Elites. En Anthropology of Elites. Power, Culture and the Complexities of Distintion, editado por T. Salverda y J. Abbkink, pp.1-28. Palgrave Macmillan, New York.

Sánchez, D. 2015. Ambiente físico-social y envejecimiento de la población desde la gerontología ambiental y geografía Implicaciones socioespaciales en América Latina. Revista de Geografia Norte Grande 60:97-114.

Sánchez, L.P., M.R. De Ávila, G.C. Castañeda, C.S. Perelis, R.D. Correio y S.D.L. Moreno, 2018. La jubilación y la sororidad femenina: una propuesta de trabajo desde las prácticas colaborativas dialógicas y las narrativas. Nova Perspectiva Sistêmica 27 (62):34-54

Sánchez-Nítola, M.N. y F. Ramírez-Cortázar 2018. Pensamiento social sobre la vejez: Actitudes y representaciones sociales. Revista Iberoamericana de Psicología 11 (2):1-16.

Sanhueza, M., M. Castro y J. Merino 2005. Adultos mayores funcionales: un nuevo concepto en salud. Ciencia y Enfermería $11(2): 17-21$

Schaffhauser, P. 2010. La dicotomía emic/etic. Historia de una confusión. Relaciones. Estudios de Historia y Sociedad 31 (121):257-269

Segato, R.L. 2013. La Crítica de la Colonialidad en Ocho Ensayos. Y una Antropología por Demanda. Prometeo, Buenos Aires.

Segato, R.L. 2016. La Guerra Contra las Mujeres. Traficantes de Sueños, Madrid.

Servicio Nacional del Adulto Mayor [SENAMA] 2010. Estudio deja al Descubierto Importantes Diferencias Según Clase, Edad, Género y Zona de Residencia ( http://www.senama.cl/ n3318_31-03-2010.html (20.marzo 2018).

Serrat, R., A. Petriwskyj, F. Villar y J. Warburton 2017. Barriers to the retention of older participants in political organisations: evidence from Spain. Ageing \& Society 37:581-606.

Subsecretaría de Desarrollo Regional y Administrativo [SUBDERE] 2005. Definición de Tipologías Comunales-Municipales. Reconociendo la Diversidad Territorial. SUBDERE, Santiago. 
Tedlock, B. 1991. From participant observation to the observation of participation: The emergence of narrative ethnography. Journal of Anthropological Research 47(1):69-94.

Treviño, S., B. Pelcastre y M. Márquez 2006. Experiencias de envejecimiento en el México rural. Salud Pública de México 48 (1):30-38

Vásquez, L. y B. Salazar 2010. Arquitectura, vejez y calidad de vida. Satisfacción residencial y bienestar social. Journal of Behavior, Health y Social Issues 2 (2):57-70.
Visweswaran, K. 2003. Defining feminist ethnography. En Turning Points in Qualitative Research: Tying Knots in a Handkerchief, editado por Y. Lincoln y N. Denzin, pp.73-94. Altamira Press, Nueva York.

Waerness, K. 1987. A feminist perspective on the new ideology of communiti care for the elderly. Acta Sociológica 30 (2):133-150.

Yuni, J.A. y Urbano, C.A. 2008. Envejecimiento y género: perspectivas teóricas y aproximaciones al envejecimiento femenino. Revista Argentina de Sociología 6 (10):151-169.

\section{Notas}

${ }^{1}$ Siguiendo a los procedimientos éticos de la investigación, se entregó a las mujeres información completa sobre los objetivos, tiempos, resultados esperados, fuentes de financiamiento, agencias financiadoras y patrocinantes, contactos con las investigadoras y limitaciones del estudio. Solamente incorporamos observaciones etnográficas de nuestra convivencia con aquellas mujeres que accedieron participar de la investigación firmando un documento jurídico de consentimiento informado. Aun de acuerdo con los procedimientos éticos de la investigación, anonimizamos las participantes del estudio, adoptando seudónimos para referirnos a ellas a lo largo de todo el texto.

2 En antropología sociocultural, los usos "emic" refieren a las expresiones y elaboraciones simbólicas, sintácticas o narrativas adoptadas por los sujetos de investigación (ver Berreman 1966; Dundes 1962; Dietz 2011; Harris 1976; Schaffhauser 2010).

${ }^{3}$ Sobre estos usos feministas en la antropología, revisar el clásico trabajo de Rosaldo y Lamphere (1974). Para un excelente ejemplo del uso de esta misma metodología narrativa que dialoga con la selección temática y de orden de los sujetos de estudio, ver el trabajo de la investigadora feminista Elizabeth Jelin (Jelin y Vila 2018).

${ }^{4}$ Intentando comprender cómo todos estos elementos se combinan en acciones concretas, autoras feministas propusieron desglosar los "trabajos de cuidado" en tres tipos de actividades de carácter práctico (Waerness 1987:134-135). El cuidado directo dirigido a las personas: incluye el cuidado físico (alimento, baño, aseo), el emocional (escuchar, hablar, ofrecer consuelo) y los servicios (comprar comida, ir de excursión). El mantenimiento físico de los alrededores donde la gente vive (cambiar la ropa de cama, lavar la ropa, limpiar el suelo). Y el trabajo de parentesco: el fomento de relaciones y conexiones sociales entre las personas (Glenn 2010:5).

${ }^{5}$ En el caso chileno, el incremento de la longevidad provoca el surgimiento de nuevas necesidades con relación a las pensiones y a la seguridad social (Giménez 2004; Marco 2004; Organización para la Cooperación y el Desarrollo Económicos [OECD] 2015), a la salud (Menéndez et al. 2005; Sanhueza et al. 2005), a la vivienda y a la accesibilidad y uso de espacios públicos (Morenos y Corregidor 2010; Sánchez 2015; Vásquez y Salazar 2010). Estas necesidades se manifiestan de modo heterogéneo: el acceso a los recursos que posibilitan el cuidado son diferenciados de acuerdo al nivel socioeconómico, al género, la localización espacial de las personas (Gonzálvez 2017).

${ }^{6}$ Bourdieu comprendía el campo "como una esfera de la vida social que se ha ido autonomizando de manera gradual a través de la historia en torno a cierto tipo de relaciones, intereses y recursos propios"
(Manzo 2010:398). Los campos sociales serían cruzados por luchas y fuerzas tendientes a la transformación y, simultáneamente, a la conservación. Funcionan debido a que los agentes "invierten en él, en los diferentes significados del término, que se juegan en él sus recursos [capitales], en pugna por ganar" (Bourdieu citado en Manzo 2010:398). Ellos están, consecuentemente, atravesados por diferentes formas de capital -social, cultural, simbólico, económicoque los sujetos van apropiando de acuerdo con las posibilidades y limitaciones que sus posiciones sociales condicionan (con relación a las jerarquías y estructuras de distinción).

${ }^{7}$ El capital cultural correspondería a los conocimientos y recursos incorporados por los sujetos y difundidos a través de sus redes sociales. Según Bourdieu (2011:214) se pueden distinguir tres estados del capital cultural: (1) incorporado; (2) objetivado y (3) institucionalizado. El primero se vincula a la noción de habitus, relacionándose con la incorporación (la adscripción corporal). Un estado que involucraría, en el contexto de nuestro estudio, nociones históricas de alteridad respecto al fenotipo, la educación formal, la estética y la presentación de las mujeres, su forma de moverse, portarse y relacionarse con otros sujetos en los espacios públicos y privados.

${ }^{8}$ Optamos por no identificar de forma explícita el CIAM donde realizamos nuestro trabajo de campo para mantener el anonimato de quienes participaron en esta investigación.

${ }^{9}$ El costo promedio de cada taller es de $\$ 14.000$ pesos y se paga de manera semestral. Las mujeres que demuestren condiciones socioeconómicas vulnerables pueden acceder a becas mediante las cuales asistir a talleres sin costo.

${ }^{10}$ Esta cifra fluctuaba hacia abajo en invierno, debido al clima y a las enfermedades estacionales, pero también debido a las complicaciones de salud asociadas al envejecimiento (diabetes, hipertensión) y a las responsabilidades de cuidado, principalmente referidas a nietos y nietas.

${ }^{11}$ Gabriela -que expresaba una clara afinidad política con los sectores de la izquierda en Chile- sostuvo su protagonismo en estas funciones incluso con el traspaso de administración municipal a un partido de derecha, en el segundo año de nuestro trabajo empírico (Diario de Campo, 03.08.2017).

${ }^{12}$ P.ej., en ciertas ocasiones, Gabriela se mostraba impaciente con algunas señoras que, tras reiteradas explicaciones, no lograban entender las instrucciones sobre cómo marcar las puntadas del bordado (Diario de Campo, 24.08.2017).

${ }^{13}$ Entre ellas, la organización de los paseos que, por lo general, eran solicitados por las mujeres "de los derechos", pero compartidos con las mujeres de los bordados (Diario de Campo, 22.10.2016) 
